\title{
Comparison and Reference of the Talent Cultivation System in Vocational Education Based on Cultural Creation and Information Industry between Fujian and Taiwan
}

\author{
Jun An Di ${ }^{1, a}$, Hao Li ${ }^{2, b}$ \\ ${ }^{1}$ Department of Electronic Information Engineering, Minjiang University, Fuzhou, Fujian China 350121 \\ ${ }^{2}$ Straits Institute, Minjiang University, Fuzhou, Fujian China 350121
}

\begin{abstract}
Fujian and Taiwan is investigated and compared in this paper. Secondly, the characteristics and advantages of the talent cultivation system in the cultural creation and information industry of Taiwan are investigated. Finally, the advantages of Taiwanese cultural creation and information industry in talent cultivation are referred to greatly cultivate the talents of cultural creation and information industry in Fujian Province.
\end{abstract}

Key words:. Education in Fujian and Taiwan, cultural creation, information industry, talent cultivation

During the twelfth five-year plan, the average growth rate of the value added of cultural creation and information industry in Fujian province was $29.8 \%$ per year, $12.8 \%$ higher than average growth rate per annum, of which the value added was $4.2 \%$ of GDP in 2010 . In the aspect of cultural trade, it was accumulated that the exported cultural and information products reached 1.52 dollars in Fujian Province from January to October of 2011, $57.1 \%$ higher than 2010 . It was also 25.6 higher than the general growth rate of the foreign export in Fujian Province in the corresponding period. The proportion of the cultural creation and information industry is increasing year by year and it is becoming a new hot of economic growth in Fujian Province and an important support to promote the development of the west bank of Taiwan. With the characteristics of high human capital, high technical content, high additional value, low energy consumption, low materials, low pollution, the cultural creation and information industry determines the human resource to be the first resource and a bottleneck to restraint this industry. Thus, it is critical for the development and cultivation of talents of this industry, especially the managers to develop this industry. However, the shortage of talents of this industry is serious increasingly with the increasing development of the cultural creation and information industry in Fujian Province.

\section{Current situation of cultural industry in Fujian} Province

The cultural industry starts late in Fujian Province, thus the talents of cultural creation, cultural management and technical innovation of cultural industry are quite lack. It cannot adapt to the rapid development of cultural industry and has become a bottleneck to

Notes: this project is funded by 2013 Fujian Branch Institute of National Vocational Education Institute (Project No. GZM13003)

About the author: Di Jun-an (1960- ), male, Professor of the Department of electronics Minjiang University), Research direction: information processing.E-mail: dmieorg@163.com

Li Hao (1980- ), male, lecturer and engineer of Minjiang University, doctoral graduate on information and communication engineering major in Wuhan University of Technology. Research direction: mobile information, electronic commerce, information communication. E-mail:eastlihao@163.com 
restraint the development of cultural industry in Fujian Province. At present, the problems, which are faced in the management and cultivation of talents of cultural industry in Fujian Province, are mainly: shortage of talent, improper talent level and structure, uncompetitive remuneration structure, imperfect talent flow market, extensive management mode, enterprises pay more attention to short-term economic benefit instead of talent cultivation, sole talent cultivation method, shortage of policy, capital and labor, etc.

\section{Improper talent level and structure}

In recent years, the colleges and universities of Fujian have set relevant majors to cultural industry, and also formed some special training institutions to cultivate the talents for cultural industry. However, the gap in the talent of cultural industry is large, such as the employees of cultural industry are lack and the talent level and structure are not proper. For example, there were 30 thousand enterprises working on cultural industry in 2014 and the employees were more than 300 thousand, but the proportion of design is $45.4 \%$, the proportion of planning is $19.4 \%$, the proportion of edition is $18.5 \%$ while the proportion of non-professional post is just $20.7 \%$, such as finance, management and administration [3]. It is closely related to the emphasis of cultural industry on professional development direction. Besides, graduates learn theories mostly and are lack of practical experience in colleges and universities although they are delivered by talent training institutions, such as universities, vocational colleges and training base of universities, so it is hard for them to input into the development and production of the cultural creation industry. For example, 17 thousand talents were lack in animation industry of Fujian Province and it was expected that there would be 43 thousand in 2015. It is hard to change the shortage of creative talent. Besides, the employee level and structure is not proper. At present, $80 \%$ of employees working on the cultural creation industry are primary practitioners ageing from 20 to 25 but only $10 \%$ has worked for more than 8 years in this industry, and over $70 \%$ of employees work for less than two years in this industry. Among them, the proportion of employees who have received technical secondary education is $54.1 \%$, the proportion of employees who has received junior college education is $24.4 \%$ and the proportion of employees who has received bachelor' $\mathrm{s}$ degree is just $23.4 \%$ 4]. Thus their quality needs to be improved further wholly.

2. Talent shortage and phenomenon of jobhopping

The cultural industry in Fujian Province is just at the initial stage, and lots of employees are from other industries, so they are lack of the systematic knowledge for cultural industry. Additionally, as a comprehensive industry, the cultural industry integrates finance, law, marketing, manufacture and so on and so it is urgent to need trans-boundary talents. However, the management system and remuneration system of cultural industry are not perfect, thus the cultivation of trans-boundary talents and free flow of high-end talents are restricted, which limits the introduction of talents to cultural enterprises. In such circumstances, lots of cultural enterprises cannot employ the professional talents, so they always pay high for the professional talents, which tend to the loss of the whole team in an enterprise, and it is a great loss for an enterprise.

The cultural industry develops early in Taiwan, so it has a relatively perfect market mechanism and talent cultivation mechanism for the development of cultural industry. The policy of cultural industry in Taiwan is always based on "how to cultivate creative talent" , "how to construct a talent cultivation system adapting to the demand of era", etc. After more than ten years of development, Taiwan has preliminarily constructed a unique talent cultivation system for cultural industry from the general education to specialization of subject of cultural industry, from basic education to vocational education and from promotion of management authority to participation of non-government institutions. Now, the cultivation of creative talents has become an important path to facilitate the development of cultural industry in Taiwan. All is worth reference for employees and policymakers of cultural industry in Fujian Province. 
(1) Cultivate professional talents by combining the international and local knowledge

According to the course content of cultural industry, the cultural creation education in Taiwan pays more attention to the development situation of the creative industry in international developed regions as well as the local culture of Taiwan. The cultivation mode of relevant majors to cultural industry in Taiwan adopts the mode of $3+1$ or $2+2$, namely they will study for two years in Taiwan and then will study for two years in those countries with developed cultural industry. Combined with the international and local knowledge, the cultivated talents can not only adapt to the demand of local market, but have a greater development space.

(2) Combination of introduced teachers and self-trained teachers

Teachers will guide the cultivation of talents of cultural industry significantly and the education of cultural creation industry in Taiwan pays more attention to the cultivation of teachers. As they cultivate the local teachers, they will also introduce foreign teachers actively to drive the development of local teachers. Besides, some teachers will also be selected to study further abroad to make the teachers of cultural industry have the advantage in international educational background and make them adapt to the international development trend.

\section{(3) Normalization of cultural creation talent} cultivation

The basic education attaches great importance to the cultural creation education in Taiwan. The philosophy of cultural creation is imported to the basic education, especially the diversified cultural creation education, such as the exploration and practice of "Nine-year System in Art \& Humanities” and construction of creative campus. The idea of cultural creation industry is used to reconsider and locate the construction of Art \& Humanities in basic education. At the same time, the general education center in Taiwanese colleges and universities also pays attention to the development of the theory and practice of cultural creation industry. As early as 2005 the
General Education Center of Feng Chia University of Taiwan held "Salon of General Education" which was featured by "Getting on the train of digital industry and cultural creation industry and becoming a winner of knowledge economy" ; the General Education Center and Creative Integration Design and Research Center of Union University and Taiwan Xiaoqu Peili Association jointly held 2008 Cultural Creation Industrial Academic Forum and Summit Forum "Global Dialogue on Earth" [12]. All these general education make the cultural creation talent cultivation normalization in Taiwan.

(4) Management department and nongovernment organization jointly cultivate the talents for industrial industry [13]

Since Taiwan government set the cultural creation industry as an important policy for regional development in 2002, the cultural construction association has been set under the promotion team of cultural creation industry of Ministry of Economy and has been responsible for the talent cultivation of cultural industry, environmental government and support of cultural industry. Some non-government profit institutions found the commercial change and actively entered the field of talent cultivation of cultural industry; some non-profit nongovernment organizations organize the cultural creation foundation and hold some lecture and courses of cultural creation. Taiwan government also transformed the government function and adjusted the governing mode as well as held the training class of cultural creation with the non-profit organizations to train the creators, operators, managers of cultural industry. And they also injected lots of fresh air to the development of cultural industrial development.

III. Learn from the advantage of talent cultivation of cultural industry and greatly cultivate the talents for industrial industry in Fujian Province

(1) Cultivate the cultural creation talents with the cooperation of colleges and universities in Fujian and Taiwan

At present the talent cultivation of the cultural industry still relies on education, and thus it is 
extremely important to improve the teaching quality. Fujian Province has a backward cultural industry higher education, so they can cooperate with Taiwanese colleges and universities and select exchange student to study in Taiwan; or employ excellent teachers from Taiwan to teach in Fujian, introduce relevant training institutions and schools to found schools or training bases related to the cultural creation and give some preference or convenient measures in tax in order to make Fujian a bass of cultural creation education and cultivate various talents for the development of cultural creation industry. In May 2009, the colleges and universities and enterprises of both sides of the Taiwan Straits signed four cooperative agreements in Creative Talent Cultivation and Industrial Cooperation Forum on both Sides of the Taiwan Straits, which greatly promoted the cultivation and communication of talents of creative industry on both sides of the Taiwan Straits, especially the cultivation and introduction of hi-end talents. On April 20, 2011 Straits Institute signed a cooperative agreement with Fujian Shaoyuan No. 1 Cultural Creation Industrial Park and held the ceremony for the production-study cooperative base. Both sides would introduce Taiwanese excellent teachers and mutually cultivate the talents for cultural creation industry through the industryuniversity-research system construction. This action guided the promotion of joint talent cultivation for cultural creation industry by Fujian and Taiwan.

(2) The colleges and universities combines with the enterprises to achieve the professional and scale cultivation of cultural creation talents. In colleges and universities, the professional teacher team generally works at school and is lack of enterprise practice, thus they are out of line with the enterprise application. It is urgent to change this situation but there is still a long way to go. It cannot be changed in short time. The vocational training can be combined with colleges and universities or higher education in the form of $2+2$ mode, namely two years of higher education are combined with two years of vocational education. The philosophy of vocational education, specific operating method, developed course system, teaching software and teaching courseware are combined with the higher education and upgraded constantly or a major is set by both sides to achieve the resource sharing and complementation at most and realize the scale cultivation of cultural creation talents. However, the talent training for cultural industry is professional and deep to some details, such as the network game development industry is involved in the training of game designer and developers and the game developers are also divided into game designer, planner and operator, especially the art staff and program developers are also refined in the market. The specialization should be resolved better in the process of such education. Without professional training, the trained talent will not adapt to and cannot meet the demand of enterprises, or they will have difficulty in employment. As a result, during the cooperation between school and enterprise, the personnel can enter enterprises for professional training based on their own major and habit as well as the market demand after learning basic theories and foundations to realize the complete connection between the talents cultivated by colleges and universities and demanded by enterprises.

(3) Keep pace with the times to cultivate and keep the cultural industry talent

The most important in cultural industry is the constant upgrading of the technology and course, because this industry develops fast and the technology upgrades fast. If teachers cannot develop at the same time and cannot catch up with the technical development, they will be eliminated and the cultivated students will also be unpopular. The talent education of cultural industry is geared to the needs of vocation and they will be undertake the research and development in the enterprise and create values for enterprises. If they learn some outdated technology, the enterprise will not be popular either. To ensure the teaching synchronization and improve the level of teachers, the source setting and teaching content must be upgraded timely in accordance with the actual situation of the development of cultural industry during teaching so that the cultivated students can adapt to the demand of enterprise. Besides, the government departments can learn from the 
areas with developed cultural industry and issue some relevant policies to provide preferential policy for talents of cultural industry and resolve the worries of employees, especially the senior employees to make them threw into the construction of cultural industry contently with heart and soul.

\section{References}

[1] CCID Consulting, Great Gap in the Planning and Creating Talents at Early Stage of Chinese Animation Industry [EB /OL], Shihua Finance Website, 2014-05-21

[2] Du Guangzhong, Development and Research of Talents of Cultural Industry in Fujian Province [J], Southeast Communication, 2013 (12)

[3] Zhang Huarong, Exploration to the New Idea of the Development of Cultural Industry [J], Open Tide, 2014

(Z1)

[4] Wei Ran, Preliminary Exploration for the Talent Cultivation System of Cultural Industry in Taiwan [J], Taiwan Research, 2013 (3)

[5] Zheng Changling and Shen Jing, Colleges and Universities and Enterprises Signed a Cooperative Agreement on Creative Talent Cultivation and Industrystudy Association [EB/OL], China News, 2009-05-17

[6] Miao Yuexia, Research on Constructing the Talent Communication Cooperative Experimental Plot of Both Sides of Taiwan Straits [J], Chinese Public Administration, 2014 (5)

[7] You Xiaobo, Thoughts about Strengthening the Communication and Cooperation of Both Sides of Taiwan Straits [EB/OL], http://tw.people. com $\mathrm{cn} / \mathrm{GB} / 21879 . \mathrm{htm}$ 